\title{
Is bed turnover rate a good metric for hospital scale efficiency? A measure of resource utilization rate for hospitals in Southeast Nigeria
}

\author{
Henry E. Aloh ${ }^{1,2^{*}}$, Obinna E. Onwujekwe ${ }^{2,3}$, Obianuju G. Aloh ${ }^{4}$ and Chijioke J. Nweke ${ }^{5}$
}

\begin{abstract}
Background: Nigeria health sector, like that of other sub-Saharan African countries, increasingly faces critical resource constraints. Thus, there is need to seek for ways of improving efficient use of scarce health resources. The aim of this study was to determine resource utilization rate of teaching hospitals in Southeast Nigeria as a means of estimating their efficiency.

Methods: The study is a longitudinal cross sectional study. It applied ratio indicators and Pabon Lasso model using data on the number of hospital bed, number of inpatients and total inpatient-days from purposefully selected teaching hospitals in Southeast Nigeria to measure efficiency over a period of 6 years (2011-2011).

Results: The hospitals' mean bed occupancy rate was as low as $42.14 \%$, far below standard benchmark of $80-85 \%$. The mean average length of stay was as high as 8.15 days and observed mean bed turnover was 21.27 patients/bed/ year. These findings portrayed high level of inefficiency in Nigeria teaching hospitals, which was further illustrated by Pabon Lasso graph, with only 10-20\% of the hospital-years located within or near the efficient zone or quadrant.

Conclusion: The study was able to show that health ratio indicators such as hospital bed turnover rate (BTR) and bed occupancy rate (BOR), as well as patients' average length of stay (ALS) can be used as tools for assessing hospital performance or its efficiency in resource utilization. Thus, in low and middle income countries where medical record keeping may be inadequate or poor, ratio indicators used alone or with Pabon Lasso graph/chart could be an optional metrics for hospital efficiency.
\end{abstract}

Keywords: Ratio indicators, Resource utilization, Pabon Lasso model, Efficiency, Teaching Hospitals, Southeast Nigeria

\section{Background}

Healthcare is one of the most important services provided by the government in every country of the world. It is regarded as a critical resource in the process of economic development. Hence, in both the developed

\footnotetext{
*Correspondence: henryealoh@gmail.com

${ }^{1}$ Health Economics and Policy Research Unit, Department of Health

Services, Alex Ekwueme Federal University Ndufu-Alike Ikwo, Ikwo, Ebonyi, Nigeria

Full list of author information is available at the end of the article
}

and developing nations, a significant proportion of the nation's wealth is devoted to the health sector. The health system in Sub-Saharan African countries including Nigeria increasingly face critical resource constraints and this is accounted for by a host of factors such as poor macroeconomic performance, cutbacks in public spending, rapid population growth, various disease outbreaks (e.g. HIV/AIDS, Lassa fever and Ebola fever), and upsurge in diseases such as malaria [1]. The health care system components such as hospitals, in developing countries has

c) The Author(s) 2020. This article is licensed under a Creative Commons Attribution 4.0 International License, which permits use, sharing, adaptation, distribution and reproduction in any medium or format, as long as you give appropriate credit to the original author(s) and the source, provide a link to the Creative Commons licence, and indicate if changes were made. The images or other third party material in this article are included in the article's Creative Commons licence, unless indicated otherwise in a credit line to the material. If material is not included in the article's Creative Commons licence and your intended use is not permitted by statutory regulation or exceeds the permitted use, you will need to obtain permission directly from the copyright holder. To view a copy of this licence, visit http://creativeco mmons.org/licenses/by/4.0/. The Creative Commons Public Domain Dedication waiver (http://creativecommons.org/publicdomain/ zero/1.0/) applies to the data made available in this article, unless otherwise stated in a credit line to the data. 
for a long time remained under resource constraint and probably inefficient [2].

Performance or efficiency evaluation of hospitals may therefore play a strategic role in healthcare organizations and help address the best use of resources and rationing of demand [3]. Performance evaluation has become central to the concept of quality improvement. It provides a means of defining what hospitals are actually doing and compare it with expected targets [4]. It enhances greater accountability and stimulates continuous quality improvement. This is why WHO Europe Regional Office lunched in 2003 a flexible and comprehensive framework called Performance Assessment Tool for quality improvement in Hospitals (PATH) [5]. Improvement in the efficiency of hospital care is a fundamental aspect of health system strengthening [6]. However, the challenges facing low-income countries is that many keep on struggling without much success to develop and implement feasible strategies to monitor hospital nationally [6].

In sub-Sahara African, hospitals play a key role in the delivery of healthcare services [7]. They also account for the bulk of government's health sector expenditure, ranging between 45 and 80\% in developing countries [8]. Empirical evidence emerging from studies in South Africa [9], in Kenya [10], in Ghana [11] and Namibia [12] indicate a wide prevalence of inefficiency in provision of hospital based healthcare. [13]. In Nigeria, hospitals are perceived to exhibit gross inefficiency [14]. This cut across all the level of healthcare. The tertiary or teaching hospitals are the highest level of healthcare in Nigeria and they take up about $60 \%$ of the country's annual budget on health.

In health systems, the nature of outputs differs from that of other organizations, thus measurements of efficiency are more difficult [15]. In hospital literatures, performance or efficiency are measured using inputs and outputs. Capital input is taken to represent a wide range of manufactured products such as complex medical equipment, buildings, beds and vehicles employed in health care. By nature capital inputs are durable and provide services over a fairly long period of time. Number of beds is the most commonly used variable in hospital efficiency studies. The use of this variable as a proxy for capital inputs has been accepted by researchers [16].

Inpatient services require that patients utilize hospital bed for an overnight stay or for extended treatment over a period of one or more days. A systemic literature reviews carried out by Iranian researchers claimed that out of about 218 indicators used in hospital performance assessment, the most frequently used are average length of stay (ALS) and bed occupancy rate (BOR) [17]. The present study used these two health ratio indicators (ALS and BOR), bed turnover rate (BTR) and turnover interval (TI), as well as Pabon Lasso model to investigate efficiency in resource utilization by Teaching Hospitals in Southeast Nigeria. It is hope that this will proof to be a simple good method for measuring performance of hospitals that treat inpatients. Thus, the study could help develop a tool or metrics for comparing hospital performance [18].

\section{Methods}

The design was cross-sectional and retrospective study. Purposeful sampling method was used to select 3 teaching hospitals that had the requisite health records from Southeast Nigeria. The region is located between longitudes $6^{\circ} 25^{\prime} \mathrm{E}$ and $8^{\circ} 30^{\prime} \mathrm{E}$, and between Latitude $5^{\circ} 10^{\prime} \mathrm{N}$ and $6^{\circ} 45^{\prime} \mathrm{N}$. The population of the region is estimated to be $20,683,115$ as at 2015 with a growth rate of $2.47 \%$ [19]. The hospitals in this study were all University Medical College health institutions, hence they function as teaching hospitals and referral centers, treating mainly chronic and complicated illnesses.

The study used health ratio indicators such as bed occupancy rate (BOR), bed turnover rate (BTR), average length of stay (ALS) and turnover interval (TI) [20] to evaluate efficiency in resource utilization of 3 teaching hospitals that were selected by simple random sampling. Data were collected for a period covering 7 years (2010 to 2016) on the following variables:

(a) Number of active beds-this refers to number of functional beds for each hospital-year.

(b) Active beds-days-this refers to the number of functional beds in the hospital for a given period, usually 1 year, and it is obtained as number of active beds multiply by 365 days.

(c) Number of admissions or discharges in a given year.

(d) Occupied-bed-days or total inpatient-days, which refers to the sum of total number of days all admitted patients spent in the hospital for a given year.

Using the above variables four ratios or indices were computed as follow [20]:

$$
\text { - Bed Occupancy Rate }(B O R)=\frac{\text { Occupied Bed }- \text { Days (Total Inpatient Days) }}{\text { Active Bed }- \text { Days }} \times 100 \%
$$


Average Length of Stay $(A L S)=\frac{\text { Occupied Bed }- \text { Days (Total Inpatient Days) }}{\text { Number of Disch } \arg \text { es }}$

- Bed Turnover Rate $(B T R)=\frac{\text { Number of Disch arg es ( } \overline{\text { or admissions) in } 1 \text { year }}}{\text { Active Beds }}$

Turnover Interval $(T I)=\frac{365}{B T R}-A L S$

The above formulae were designed into a stata11 version of Microsoft Excel spread sheet for easier computation.

The study went on to apply Pabon Lasso model or graph to further demonstrate efficiency of the hospitalyears, since using any one of the above indicators alone may not sufficiently estimate performance or efficiency of the hospitals. Pabon Lasso Model was originally developed by Pabon Lasso in 1986, and it is a technique used for interpreting and comparing hospital efficiency using three indices [21]. Mathematically, correlations of the 3 indicators were shown by plotting BTR on the y-axis and $\mathrm{BOR}$ on the $\mathrm{x}$-axis [22]. And using the average of the two indices (BTR and BOR) 2 perpendicular lines were drawn to divide the graph into four quadrants or zones. The Pabon Lasso diagram obtained was then used as performance assessment tool [23, 24]. Thus, using the four quadrants/zones of the graph, efficiency of various hospital-years were known and the manner with which they utilized available resources are also made clear.

\section{Results}

The record of active hospital beds, as well as number of inpatients and inpatient-days for respective Teaching Hospitals, between year 2010 and 2016 (7 years period), are shown in Table 1. The average (mean) active hospital bed spaces for the hospital-years was 380 beds. The average yearly number of admissions was 8394 inpatients per hospital per year. FETHA had the highest number of admitted patients of 14,037 during the period. While the mean inpatient-days for all the hospitals was 56,912 per year, the highest was UNTH inpatient-days of 85,056 in 2012 (as shown in Table 1 below).

Table 2 show that the overall mean bed occupancy rate (BOR) of the hospitals during the period was $42.14 \%$, and the values range between $22.62 \%$ and $62.37 \%$ among the hospital-years. Mean bed turnover rate (BTR) was 22 patients per bed per year, and the BTR was as low as about 7 patients per bed per year for ESUTH in 2011. The highest value of about 34 patients/bed/year for FETHA was recorded in 2011. Mean average length of stay (ALS) for admitted patients in this study was as high as 8.15 days and the least mean ALS was 3.27 days for FETHA in 2012. The mean turnover interval (TI) for the hospitals was as high as 10.19 days. The shortest average TI for the hospitals was recorded by FETHA as 8.04 days. Thus, apart from long stay of admitted (ALS) patients, all the 3 hospitals exhibited protracted turnover interval (ESUTH-10.72 days and UNTH-11.83 days). Pabon Lasso graph in Fig. 1 emanated from plotting of BTR against BOR.

The location of each hospital-years in any of the Pabon Lasso quadrants in Fig. 1 describe the level and type of efficiency of such hospital-year. Hospital-years in zone-1 (Low BTR and low BOR) exhibit relatively excess bed supply, less need for hospitalization and low demand/utilization. Zone-ii (high BTO and low BOR) refers to excess bed capacity, unnecessary hospitalization, too many patients being admitted for observation or predominant normal obstetric delivery. The efficient zone - iii (high BTO and high BOR) infers that the hospital-years in this zone had good quantitative performance and small proportion of unused beds. The fourth quadrant (low BTO and high BOR) host hospital-years that had low demand for hospital beds, yet had small proportion of its beds unused. About $20 \%$ of the hospital-years were situated in the least efficient quadrant-I, $30 \%$ of the hospital-years were located in quadrant-II; while only $10 \%$ of the hospital-years were situated in the efficient quadrant-III and $40 \%$ of the hospital-years were found in quadrant-IV. It was observed that most of the FETHA hospital-years were located in the second Pabon Lasso quadrants that is characterized by high BTR, low BOR. Two (2) of the hospital-years of ESUTH were located in the efficient quadrant.

\section{Discussion}

It is widely accepted that improved efficiency is one of the four overarching goals of health systems [25]. The World Health Report 2014 estimated that about $20-40 \%$ of all health sector resources are wasted [26]. One of the vital approach to reducing resource waste is to enhance efficiency in utilization of available resource [27]. And the starting point in doing so is to undertake performance or efficiency assessment [28]. It is useful in guiding hospital manager at micro level and health policy makers in government at macro level [29].

The present study investigated the efficiency of resource utilization among University Teaching hospitals in Southeast Nigeria; it compared the performance of the hospitals over a period of 7 years (2010-2016). Four ratio indicators: bed occupancy rate (BOR), average length of stay (ALS), bed turnover rate (BTR) and turnover 
Table 1 Descriptive Statistics of Hospital Resources (beds) and Patients admission (2010 - 2016)

\begin{tabular}{|c|c|c|c|c|}
\hline Hospital-years & No. of active hospital beds & Active-bed-days & No. of inpatients & Inpatient-days \\
\hline FETHA 2011 & 223 & 81,395 & 7657 & 32,751 \\
\hline FETHA 2012 & 486 & 177,390 & 13,400 & 43,863 \\
\hline FETHA 2013 & 489 & 178,485 & 14,253 & 53,660 \\
\hline FETHA 2014 & 512 & 186,880 & 16,982 & 61,388 \\
\hline FETHA 2015 & 533 & 194,545 & 14,885 & 62,381 \\
\hline FETHA 2016 & 513 & 187,245 & 17,043 & 59,634 \\
\hline FETHA Mean & 459.33 & $167,656.67$ & 14,037 & $52,279.5$ \\
\hline ESUTH 2010 & 244 & 89,060 & 3359 & 30,238 \\
\hline ESUTH 2011 & 244 & 89,060 & 1670 & 20,144 \\
\hline ESUTH 2012 & 260 & 94,900 & 5152 & 56,672 \\
\hline ESUTH 2013 & 260 & 94,900 & 5433 & 48,897 \\
\hline ESUTH 2014 & 260 & 94,900 & 4220 & 54,860 \\
\hline ESUTH 2015 & 342 & 124,830 & 6698 & 53,584 \\
\hline ESUTH 2016 & 320 & 116,800 & 8094 & 72,846 \\
\hline ESUTH Mean & 275.71 & $100,635.71$ & 4947 & $48,177.29$ \\
\hline UNTH 2010 & 424 & 154,760 & 6635 & 66,795 \\
\hline UNTH 2011 & 424 & 154,760 & 8061 & 84,675 \\
\hline UNTH 2012 & 424 & 154,760 & 8533 & 85,056 \\
\hline UNTH 2013 & 411 & 150,015 & 8300 & 85,003 \\
\hline UNTH 2014 & 411 & 150,015 & 5528 & 55,057 \\
\hline UNTH 2015 & 411 & 150,015 & 4578 & 43,119 \\
\hline UNTH 2016 & 411 & 150,015 & 7399 & 67,625 \\
\hline UNTH Mean & 416.57 & $152,048.57$ & 7005 & $69,618.57$ \\
\hline Mean & 380.1 & $138,736.5$ & 8394 & $56,912.4$ \\
\hline Minimum & 223 & 81,395 & 1670 & 20,144 \\
\hline Maximum & 533 & 194,545 & 17,043 & 85,056 \\
\hline
\end{tabular}

FETHA is Federal Teaching Hospital Abakaliki, ESUTH is Enugu State Teaching

Hospital and UNTH is University of Nigeria Teaching Hospital

interval (TI) were used to do so. Demonstration of hospital efficiency were elucidated using Pabon Lasso model or graph.

Bed occupancy rate (BOR) is a measure of utilization of the available bed capacity in the hospital, and it indicates the percentage of beds occupied by patients in a given period of time, usually 1 year. It reflects efficiency in the use of hospital beds. And hospital can be said to be operating efficiently at BOR of $80-90 \%$ [30]. Among all the hospital-years in the present study the maximum BOR of $62.37 \%$ was observed for ESUTH in 2016. Within the seven years period the mean BOR for the hospitals was abysmally as low as $42.14 \%$. Similar study in Uganda hospital over a period of 10 years show that the average BOR was as much as $78.8 \%$ [31]. Younsi (2014) in a comparative assessment got a value of $58.1 \%$ as mean BOR for 40 public hospitals in Tunisia [32]. A more recent evaluation in Uganda, Sub-Saharan African country, showed average BOR of $49.35 \%$ (and BTR of 74.0 times per year and ALS of 3.63 days) [33]. In Iran and other
Middle East countries the use of ratio measurement as a means of assessing hospital efficiency is common. Recent studies in different part of Iran showed an average BOR of $65.40 \%$ [34], 62.63-69.56\% [35], 65.91\% [36], as against Iranian national BOR average of $57.8 \%$. The mean BOR obtained from the present study was still below the BOR of $56-61 \%$ among public hospitals in Malaysia between 2006 and 2010 [37]. In recent years BOR in countries such as Indonesia range between 55 and $60 \%$ in both public and private hospitals, as compared to $80 \%$ average for South-East Asian region hospitals [38]. The conventionally suggested benchmark for hospital BOR is $85 \%$ [31], signifying that the mean BOR of $42.14 \%$ in the present study was relatively very low. And thus, the teaching hospital could be said to have exhibited high level of inefficiency in the utilization of hospital beds during the period under review.

Average length of stay (ALS) refers to the number of days each admitted patient stayed in the hospital. It is often better to compare homogenous group of hospitals 
Table 2 Health ratio indicator expressing resource utilization rate of hospitals

\begin{tabular}{|c|c|c|c|c|}
\hline Hospital-year & $\begin{array}{l}\text { Bed occupancy rate (BOR) } \\
\text { in } \%\end{array}$ & $\begin{array}{l}\text { Average length of stay (ALS) } \\
\text { in days }\end{array}$ & $\begin{array}{l}\text { Bed turnover rate (BTR) in patients } \\
\text { per bed per year }\end{array}$ & $\begin{array}{l}\text { Turnover } \\
\text { interval (TI } \\
\text { in days) }\end{array}$ \\
\hline FETHA 2011 & 40.24 & 4.28 & 34 & 6.35 \\
\hline FETHA 2012 & 24.73 & 3.27 & 28 & 9.96 \\
\hline FETHA 2013 & 30.06 & 3.76 & 29 & 8.76 \\
\hline FETHA 2014 & 32.85 & 3.61 & 33 & 7.39 \\
\hline FETHA 2015 & 32.07 & 4.19 & 28 & 8.88 \\
\hline FETHA 2016 & 31.85 & 3.50 & 33 & 7.49 \\
\hline FETHA Mean & 31.97 & 3.77 & 31 & 8.04 \\
\hline ESUTH 2010 & 33.95 & 9.00 & 14 & 17.51 \\
\hline ESUTH 2011 & 22.62 & 12.06 & 7 & 41.27 \\
\hline ESUTH 2012 & 59.71 & 11.00 & 20 & 7.42 \\
\hline ESUTH 2013 & 51.52 & 9.00 & 21 & 8.47 \\
\hline ESUTH 2014 & 57.81 & 13.00 & 16 & 9.49 \\
\hline ESUTH 2015 & 42.93 & 8.00 & 20 & 10.64 \\
\hline ESUTH 2016 & 62.37 & 9.00 & 25 & 5.43 \\
\hline ESUTH Mean & 47.27 & 10.15 & 18 & 10.72 \\
\hline UNTH 2010 & 43.16 & 10.07 & 16 & 13.26 \\
\hline UNTH 2011 & 54.71 & 10.50 & 19 & 8.69 \\
\hline UNTH 2012 & 54.96 & 9.97 & 20 & 8.17 \\
\hline UNTH 2013 & 56.66 & 10.24 & 20 & 7.83 \\
\hline UNTH 2014 & 36.70 & 9.96 & 13 & 17.18 \\
\hline UNTH 2015 & 28.74 & 9.42 & 11 & 23.35 \\
\hline UNTH 2016 & 45.08 & 9.14 & 18 & 11.14 \\
\hline UNTH Mean & 45.72 & 9.90 & 17 & 11.83 \\
\hline Mean & 42.14 & 8.15 & 21 & 10.19 \\
\hline Minimum & 22.62 & 3.27 & 7 & 5.43 \\
\hline Maximum & 62.37 & 13.00 & 34 & 41.27 \\
\hline
\end{tabular}

FETHA is Federal Teaching Hospital Abakaliki, ESUTH is Enugu State Teaching

Hospital and UNTH is University of Nigeria Teaching Hospital

that have a similar case-mix. The hospitals studied here were all university teaching hospitals and are known for treating mainly referred and often chronically sick clients. Hospital(s) or hospital-years with shorter ALS than its peers could be regarded to be performing relatively better than those with higher ALS. In this study the lowest ALS was observed for FETHA with a mean ALS of 3.77 days. The explanation for this is either that FETHA was more efficient than the other teaching hospitals in terms of effectiveness in treatment of its patients and in terms of shortening of patients hospital stay. It may also be that FETHA tend to treat more number of acutely ill patients than these other hospitals. The mean ALS for all the hospitals was about 8.15 days. Previous studies on hospitals affiliated to medical school in Iran exhibited mean ALS of 4.1 days [35], 3.21 days [39] and 4.084.59 days [40]. This, again show that the hospitals in the present study were less efficient.
Bed turnover rate (BTR) measures productivity of hospital beds, and it represent the number of patients treated per bed in a defined period, usually 1 year. BTR of chronic care hospitals such as orthopedic or teaching hospitals are expected to be lower than those of acute care hospitals. The BTR of the teaching hospitals in this study for the various years were between 6.84 and 34.34 patients per bed per year, with a mean BTR of 21.27 patients per bed per year. This again demonstrate low productivity and high level of inefficiency. The highest value of BTR obtained being that of FETHA with a mean BTR of 30.89 patients/bed per year. The BTR of the hospital-years were all quite low, compared to that of their Iranian counterpart hospitals that are affiliated to medical school, where the BTR were observed to be between 61.10 and 95.54 patients per bed per year [24, 35, 36, 40, 41].

On the other hand, turnover interval (TI) is referred to as measure of the average times or days that hospital 


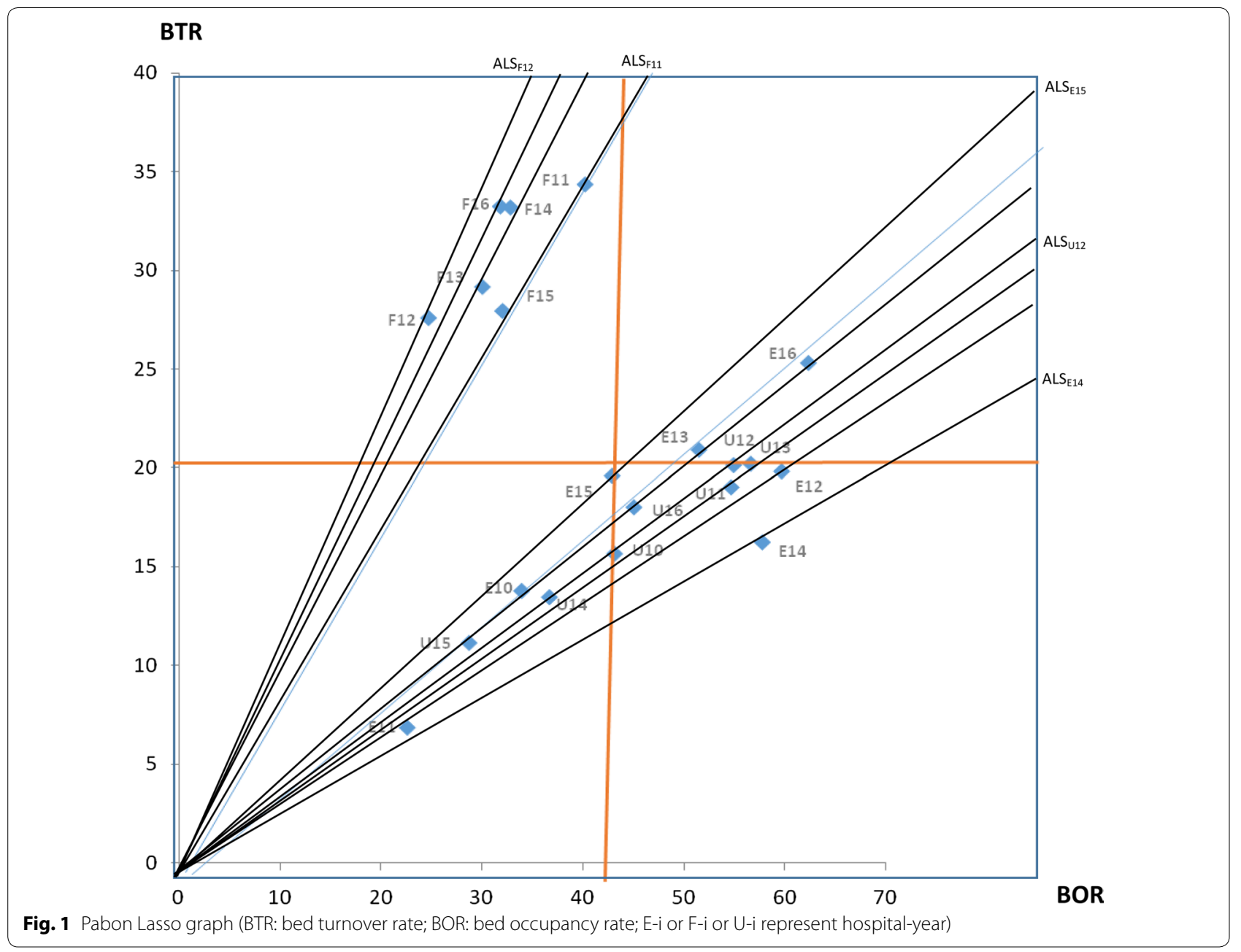

beds are unoccupied between successive inpatients. The higher the value of TI of hospital, the less efficient the hospital is. The ideal turnover interval is suggested to be 1-3 days. In the present study all the TI obtained were between 5.43 and 41.27 days with overall mean TI of 10.19 days. This portrays high level of inefficiency or poor performance in terms of hospital bed utilization.

Assessment of hospital performance based on any single ratio indicators may sometime be misleading. Pabon Lasso (1986) had devised a model or graph that makes use of 3 of these ratio indicators (BOR, ALS and BTR) to assess relative performance of hospitals [21]. The plotting of BTR on the vertical axis, BOR on the horizontal axis and the use of mean values of these two ratios to divide the graph into four quadrants is what is known as Pabon Lasso graph [21]. The various hospital-years were located into these four different quadrants. About $20 \%$ of the hospital-years were located in the most inefficient quadrants that is characterized by low bed turnover and low bed occupancy rate. The hospital-years located in this quadrant experienced high un-utilize hospital beds. As much as $30 \%$ of the hospital-years, mainly from FETHA, were located in quadrant-II. These hospital-years were characterized by high turnover rate, low bed occupancy rate and relatively short stay in hospital by patients. The possible explanation is that there might have been too many un-necessary hospital admission or treatment of many acutely ill patients.

Only $10 \%$ of hospital-years were located within the efficient quadrant-III and another $10 \%$ were located very close to it. These small fraction of hospital-years exhibited appropriate efficient level or performance. The hospitals enjoyed high bed occupancy and high bed turnover rate in 2013 and 2016. High BTR and BOR implies efficiency or ability of the hospital to efficiently utilize available resources $[21,26]$. The study further revealed that the majority $(40 \%)$ of the hospital-years that were located in quadrant-IV, which were characterized by high occupancy rate, low turnover and long hospital stay. This is not surprising; since the hospitals studied were teaching 
hospital that usually or often admitted chronically sick patients. Hospital-years in this zone were mainly those of UNTH and that of ESUTH. The findings indicate clearly that half of the hospital-years relatively exhibited high bed occupancy rate (as shown by quadrants-III and -IV). However, in terms of a wholesome efficient performance, the Pabon Lasso graph was able to demonstrate that only as few as $10 \%$ of hospital-years were efficient. Thus, the hospitals were unable to efficiently utilize their available capital resources during the period under review (20062011). This is in agreement with the result of a recent systemic review of hospital efficiency in East Mediterranean region which show that excess bed supply and inappropriate hospital size are some of the major causes of inefficiency [42].

\section{Conclusion}

Efficiency is widely used in health economics and it simply refers to wise utilization of resources in production of health services. The present study undertook appraisal of teaching hospital performance in the Southeast Nigeria by analyzing their resource utilization rate, covering a period of 2010 to 2016; the findings include: low bed occupancy rate and high average length of stay for the patients. This, is strong evidence of inefficiency among the teaching hospitals in Southeast Nigeria. These observations were emphatically expressed by location of a large proportion $(80-90 \%)$ of the hospital-years outside the efficient quadrant of Pabon Lasso model.

\section{Limitations of the study}

This study suffers from some limitations upon which future studies should improve upon.

(1) Poor quality of health information and record/data keeping among the hospitals is of great concern. In some instance to ensure completeness, data were collected in peace-meal from many departments, instead of the designated Health Record Department.

(2) The ratios indicators as a method of measuring hospital performance can only be applied on hospitals that provide inpatient services.

\section{Recommendations}

There is need for various government to make efficiency a policy objective and institutionalize health facility efficiency monitoring and evaluation as a basis for the design and implementation of appropriate policy interventions, and as a means of curbing wastage of health system inputs (WHO, 2014). Health efficiency monitoring should be used as a tool within health management information system (HMIS) of various ministries of health, both at State or Regional level or National level.

\section{Acknowledgements}

We are very grateful to the management and medical record departments of all the participating teaching hospitals for their cooperation and assistance.

\section{Authors' contributions}

HEA conceptualized the study and wrote the first draft of the manuscript. OGA collected the data. OEO contributed to the design of the study and reviewed of the manuscript. CJN analysed the data. All authors read and approved the final manuscript.

\section{Funding}

Private funding.

\section{Availability of data}

Datasets used and analyzed for the study are available and maybe released by the corresponding author on reasonable request.

\section{Ethics approval}

Ethical approvals were obtained from respective ethical committee of the participating hospitals.

\section{Consent for publication}

Not applicable.

\section{Competing interests}

The authors declare that they have no competing interests.

\section{Author details}

${ }^{1}$ Health Economics and Policy Research Unit, Department of Health Services, Alex Ekwueme Federal University Ndufu-Alike Ikwo, Ikwo, Ebonyi, Nigeria. ${ }^{2}$ Department of Health Administration \& Management, Faculty of Health Sciences, College of Medicine, University of Nigeria Enugu Campus, Nsukka, Nigeria. ${ }^{3}$ Health Policy Research Group, Department of Pharmacology and Therapeutics, College of Medicine, University of Nigeria Enugu Campus, Nsukka, Nigeria. ${ }^{4}$ Primary Health Development Agency, Ministry of Health, Abakaliki, Ebonyi, Nigeria. ${ }^{5}$ Department of Mathematics/Computer Sciences/ Statistics \& Informatics, Alex Ekwueme Federal University Ndufu-Alike Ikwo, Ikwo, Nigeria.

Received: 19 September 2019 Accepted: 20 June 2020 Published online: 01 July 2020

References

1. World Health Organization (2015). Country statistics and global health estimates by WHO and UN partner (Nigeria: WHO statistical profile). http://www.who.int/gho/countries/nga.pdf.

2. Kong X, Yang Y, Gao J, Guan J, Liu Y, Wang R, Xing B, Li Y, Ma W. Overview of the health care system in Hong Kong and its referential significance to mainland China. J Chin Med Assoc. 2015;78:569-73.

3. Matranga D, Bono F, Casuccio A, Firenze A, Maesala L, Giaimo R, Sapienza F, Vitale F. Evaluating the effect of organization and context on technical efficiency; a second-stage DEA analysis of Italian hospitals. Epidemiol Biostat Public Health. 2014;11(1):87851-878511.

4. Shaw C. How can hospital performance be measured and monitored? Copenhagen, WHO Regional Office for Europe (Health Evidence Network report. 2013; http://www.euro.who.int/document/e82975.pdf).

5. Veilland J, Champagne F, Klapinga N, Kazandjian V, Arah AO, Guisset L. A performance assessment framework for hospitals: the WHO regional office for Europe PATH project. Int J Qual Health Care. 2005;17(6):487-96. 
6. McNatt Z, Linnander E, Endeshaw A, Tatek D, Conteh D, Bradley BH. A national System for monitoring the performance of Hospitals in Ethiopia. WHO Bull. 2015;93(10):719-26.

7. Akazili J, Adjuik M, Chatio S, Kanyomse E, Hodgson A, Aikins M, Giapong J. What are the technical and allocative efficiencies of Public Health Centres in Ghana? Ghana Med J. 2008;42(4):149-55.

8. Bahadori M, Sadeghifar J, Hamonzadeh M, Nejati M. Combining multiple indicators to assess hospital performance in Iran using the Pabon Lasso Model. Australas Med J. 2011:4(4):175-9.

9. Zere E. Hospital Efficiency in Sub-Saharan Africa: Evidence from South Africa. UNU World Institute for Development Economic Research, Helsinki, Finland: working 2000; Paper.No. 187.

10. Kirigia JM, Emrouznejad A, Sambo LG. Measurement of technical efficiency of public hospitals in Kenya: using data envelopment analysis. J Med Syst. 2002;26(1):39-45.

11. Osei D, George M, Almeida S, Kirigia JM, Mensah AO, Kainyu LH. Technical efficiency of public district hospitals and health centres in Ghana: a pilot study. Cost Eff Resourc Alloc. 2005;3(9):1-13.

12. Zere E, Shangula K, Mandlhate C, Mutirua K, Tjivambi B, Kapenambili W. Technical Efficiency of District Hospitals: Evidence from Nambia Using DEA. Cost Effectiveness and Resource allocation. 2006;4:5.

13. Odhiambosa J, Wambugu A, Kiriti-Nganga T. Effect of health expenditure on child health in Sub-Saharan Africa: government perspective. J Econ Sust Dev. 2015;6(8):43-65.

14. Kpamor Z. Nigeria's health statistics and trends: the Woodrow Wilson Intl Isboa, Lisbon, Portugal. Eur J Public Health. 2012;25(4):52-8.

15. Masoompour MS, Petramfar P, Farhadi P, Mahdaviazad H. Five-year trend analysis of capacity utilization measures in a teaching hospital 2008-2014. Shiraz E-Med J. 2015;16(2):ez1176.

16. Kawaguchi H, Tone K, Tsutsui M. Estimation of the efficiency of Japanese hospitals using a dynamic and network data envelopment analysis model. Health Care Manag Sci. 2014;17:101. https://doi.org/10.1007/ s10729-013-9248-9.

17. Bahadori M, Izadi AR, Ghardashi F, Ravangard R, Hosseini SM. The evaluation of hospital performance in Iran: a systematic review article. Iran J Public Health. 2016:45(7):855-66.

18. Davis P, Milne B, Parker K, Hider P, Lay-Yee R, Cumming J, Graham P. Efficiency, effectiveness, equity (E3). Evaluating hospital performance in three dimensions. Health Policy. 2013;112:19-27.

19. Nigeria National Population Commission (NNPC) [Nigeria] and ICF Macro. Nigeria Demographic and Health Survey 2008. Abuja: National Populaton Commission and ICF Macro; 2008. p. 2015.

20. Mehrtak M, Yusefzadeh H, Jaafaripooyan E. Pabon Lasso and data envelopment analysis: a complementary approach to hospital performance measurement. Glob J Health Sci. 2014;6(4):107-16.

21. Pabon LH. Evaluating hospital performance through simultaneous application of several indicators. Bull Pan Am Health Org. 1986:20(4):341-57.

22. Adham D, Panah M, Barfar I, Amari H, Sadeghi G, Salarikhah E. Contemporary use of hospital efficiency indicators to evaluate hospital performance using the Pabon Lasso Model. Eur J Bus Soc Sci. 2014;13(2):1-08.

23. Mehrolhasani M, Fayzabad VY, Shahrbabak TB. Assessing performance of Kerman province's hospitals using Pabon Lasso Diagram between 2008 and 2010. J Hosp. 2014;12(4):99-108.

24. Goshtasebi A, Vahdaninia M, Gorgipour R, Samanpour A, Maftoon F, Farzadiand F, Ahmadi F. Assessing, hospital performance by Pabon Lasso model. Iran J Public Health. 2009;38(2):119-24.

25. World Health Organization (WHO). Global health expenditure atlas. Geneva: World Health Organization. http://www.who.int/health-accou nts/atlas2014.pdf.

26. Mohebbifar R, Sokhanvar M, Hasanpoor E, Isfahani HM, Ziaiifar H, Kakenam E, Mohseni A. Survey on the performance of hospitals of Qazvin province by the Pabon Lasso model. Int Res J Biol Sci. 2014;3(12):5-9.

27. Mujasi PN, Asbu EZ, Puig-Junoy J. How efficient are referral hospitals in Uganda? A data envelopment analysis and Tobit regression approach. BMC Health Serv Res. 2016;8(16):230.
28. Renner A, Kirigia JM, Zere EA, Barry SP, Kirigia DG, Kamara C, Muthuri LHK. Technical efficiency of peripheral units in Pajehun District of Sierra Leone: a DEA application. BMC Health Serv Res. 2005;5(77):1-12.

29. Kirigia MM, Asbu EZ, Kirigia DG, Onwujekwe OE, Fonta WM, Ichoku HE. Technical efficiency of human resources for health in Africa. Eur J Bus Manag. 2011;3(4):321-45.

30. Barnum H, Kutzin J. Public hospitals in developing countries: Resource use, cost, financing. Baltimore: Johns Hopkins University Press; 1993.

31. Accorsi S, Corrado B, Fabiani M, Iriso R, Nattabi B, Ayella EO. Competing demands and limited resources in the context of war, poverty and disease: the case of Lacor hospital. Health Policy Dev J. 2003;1:29-39.

32. Younsi M, Chakroun M. Measuring health-related quality of life: psychometric evaluation of the Tunisian version of the SF-12 health survey. Qual Life Res. 2014;23(7):93. https://doi.org/10.1007/s11136-014-0641-8.

33. NabuKeera M, Boerhannoeddin A, Raja Noriza RA. An evaluation of health centers and hospital efficiency in Kampala capital city authority Uganda: using Pabon Lasso technique. J Health Transl Med. 2015;18(1):12-7. https ://doi.org/10.5430/wjss.v1n2p86.

34. Ghobad M, Bakhtiar P, Hossein S, Nader EN, Amjad MB, Arezoo Y. Assessment of the efficiency of hospitals before and after the implementation of Health Sector Evolution Plan in Iran Based on Pabon Lasso Model. Iran J Public Health. 2017:46(3):389-95.

35. Kalhor R, Salehi A, Kechavarz A, Bastani P, Orojloo PA. Ssessing hospital performance in Iran using the Pabon Lasso model. Asia Pac J Health Manag. 2014;9(2):77-82

36. Lotfi F, Kalhor R, Bastani P, Zadeh NS, Eslamian M, Dehghani MR, Kiaee M. Various indicators for the assessment of hospitals' performance status: differences and similarities. Iran Red Crescent Med J. 2014;16(4):1-7.

37. Nwagbara VC, Rasiah R. Rethinking health care commercialization: evidence from Malaysia. Glob Health. 2015;11(1):44. https://doi.org/10.1186/ s12992-015-0131-y.

38. Awofeso N, Rammohan A, Asmaripa A. Exploring Indonesia's "low hospital bed utilization-low bed occupancy-high disease burden" paradox. J Hosp Adm. 2013;2(1):49-58

39. Goudarzi R, Pourreza A, Shokoohi M, Askari R, Mhdavi M, Moghri J. Technical efficiency of teaching hospitals in Iran: the use of Stochastic Frontier Analysis, 1999-2011. Int J Health Policy Manag. 2014;3(2):91-7.

40. Kalhor R, Ramandi F. D., Rafiel, S., Rafiel, S., et al. (2016). Performance analysis of hospitals affiliated to Mashhad University of medical sciences using Pabon Lasso model: A six year trend study. Biotech Health Sci. 3(4).

41. Gholipour K, Delgoshai B, Masudi-Asl I, Hajinabi K, lezadi S. Comparing performance of Tabrz obstetrics and gynawecology hospitals manged as autonomous and budgetary units using Pabon Lasso method. Australas Med J. 2013;6(12):701-7.

42. Ravaghi $H$, Afshari $M$, Isfahani P, Bélorgeot VD. A systematic review on hospital inefficiency in the Eastern Mediterranean Region: sources and solutions. BMC Health Serv Res. 2019;19:830. https://doi.org/10.1186/ s12913-019-4701-1.

\section{Publisher's Note}

Springer Nature remains neutral with regard to jurisdictional claims in published maps and institutional affiliations.

Ready to submit your research? Choose BMC and benefit from:

- fast, convenient online submission

- thorough peer review by experienced researchers in your field

- rapid publication on acceptance

- support for research data, including large and complex data types

- gold Open Access which fosters wider collaboration and increased citations

- maximum visibility for your research: over 100M website views per year

At $\mathrm{BMC}$, research is always in progress.

Learn more biomedcentral.com/submissions 